\title{
Assessment of vitamin E, selenium and polyunsaturated fatty acid interactions in the aetiology of disease in the bovine
}

By Desmond A. Rice and Seamus Kennedy, Veterinary Research Laboratories, Stoney Road, Belfast BT4 3SD

In the past 10 years there have been major advances in our understanding of the production and function of eicosanoids. These cyclo-oxygenase and lipoxygenase derivatives of $\mathrm{C}_{20}$ polyunsaturated fatty acids (PUFA) have a variety of beneficial effects. However, during the process of PUFA release from subcellular membranes and the enzymic production of these potent tissue hormones, a variety of peroxides and free radicals are formed. If not rapidly detoxified these can lead to a chain-reaction production of lipid free-radicals and peroxides in the phospholipid PUFA which is contiguous to, but not directly involved in, this enzymic oxidation process. If uncontrolled this damage will produce pathological sequelae which can affect a wide variety of animals and a great diversity of tissues and diseases (Table 1). Fortunately, nature has provided a variety of mechanisms for minimizing this peroxidative damage to cells, two of the principal agents being vitamin $E$ and selenium.

The Stormont laboratory has been involved for a number of years in studies on the aetiology of these diseases, particularly nutritional degenerative myopathy of steers. Our work has demonstrated that myopathy in this species is aetiologically related to dietary vitamin $E$ ( $\alpha$-tocopherol) and Se (glutathione peroxidase; EC 1.11.1.9; GSH-Px) deficiency and PUFA excess. It indicates that future studies on the pathophysiological processes resulting from imbalances of these nutrients should avoid experimental protocols which study each as an individual entity ignoring the close inter-dependence which they display. It has also demonstrated that availability of these nutrients should be considered not merely in terms of dietary inputs but more importantly in terms of the effect of these inputs on incorporation of these nutrients into the target cell or organelle where they are required.

Table 1. Examples of the diversity of livestock species and target tissues affected by vitamin $E$ and selenium deficiencies and the varied pathologies resulting from these deficiencies

\begin{tabular}{|c|c|c|}
\hline Tissue & Species affected & Pathological sequelae \\
\hline Skeletal muscle & $\begin{array}{l}\text { Turkey, chicken, lamb, } \\
\text { calf, pig }\end{array}$ & Myopathy (all species) \\
\hline Cardiac muscle & $\begin{array}{l}\text { Turkey, chicken, lamb, } \\
\text { calf, pig }\end{array}$ & $\begin{array}{l}\text { Myopathy (all species) } \\
\text { Purkinje fibre damage (bovine) } \\
\text { Vascular damage (pig) }\end{array}$ \\
\hline Liver & Pig, bovine, fish & $\begin{array}{l}\text { Necrosis (pig) } \\
\text { Telangiectasis (bovine) } \\
\text { Lipoid degeneration (fish) }\end{array}$ \\
\hline Vascular system & Pig, chicken, turkey & $\begin{array}{l}\text { Mulberry heart disease (pig) } \\
\text { Exudative diathesis (chicken, turkey) }\end{array}$ \\
\hline Pancreas & Chicken, mouse, fish & Fibrosis (all species) \\
\hline Cerebellum & Chick & Encephalomalacia \\
\hline Adipose tissue & $\begin{array}{l}\text { Pig, horse, chick, } \\
\text { mink }\end{array}$ & Steatosis/Steatitis (all species) \\
\hline Uterus & Bovine & Retained placentae \\
\hline
\end{tabular}




\section{PUFA}

The eicosanoid profile resulting from the action of cyclo-oxygenase and lipoxygenase on PUFA released from subcellular membranes depends to a large extent on the fatty acid composition of the phospholipids in the membrane. This fatty acid profile is governed by two main factors. First, each tissue and subcellular membrane is genetically programmed to maintain a predetermined fatty acid profile, so that each tissue and subcellular membrane type will have a unique fatty acid profile under a given dietary regimen. This profile is required for optimum membrane fluidity, transport activity and provision of optimum laterally segregated lipid domains for enzyme receptor sites (for review see Stubbs \& Smith, 1984).

In addition, the PUFA profile of subcellular phospholipids can be modified by the dietary input of lipid. Increasing dietary $n-6$ and $n-3$ series PUFA or dietary saturated fatty acids will result in increases in the concentration of that specific dietary fatty acid and its chain-elongated and desaturated family members in the phospholipids of the animal consuming them. The effect of such dietary PUFA modifications on the immune status of the animal has been reviewed by Gurr (1983). More specifically the effect on eicosanoid production has been reviewed by Johnston (1985). This aspect will not be discussed here, suffice it to say that there is now little doubt that increasing the concentration or proportion, or both, of $n-3$ series fatty acids in the diet will beneficially modulate prostanoid synthesis with the associated clinical advantages of decreased risk of coronary heart disease, micro-thrombosis and immune-related inflammatory disease.

These beneficial effects must also be weighed against any potential detrimental effects. Studies at our laboratory have shown that increased dietary inputs of both $n-6$ and $n-3$ series PUFA can have detrimental effects, particularly where the vitamin E-Se status of the animal tissues is suboptimal (McMurray et al. 1983). Our studies currently involve modulation of dietary $n-3$ fatty acid input of yearling cattle using a vitamin E- and Se-deficient diet based on sodium hydroxide-treated barley (Rice \& McMurray, 1986) to which linolenic acid $\left(C_{18: 3}, n-3\right)$ is added as protected fat (Rice et al. 1981).

We have previously shown that nutritional degenerative myopathy can be induced in vitamin $E$ - and Se-deficient steers either in a chronic form as a result of long-term vitamin E and Se depletion, with no added fat (Rice \& McMurray, 1986), or in an acute form by feeding to these depleted animals either grass (which is high in $C_{18: 3}, n-3$ ) or the equivalent amount of $\mathrm{C}_{18: 3}, n-3$ in the form of protected linseed oil (Rice \& McMurray, 1982; McMurray et al. 1983). As the grass or protected linseed oil produced an increased concentration of $\mathrm{C}_{18: 3}, n-3$ in plasma acute myopathy was produced concurrently, usually within only 2-6 d of feeding. Our recent work has examined the effect of the dietary regimens used in this experimental model on the fatty acid composition of tissues (Rice et al. 1986). We found that feeding $\mathrm{NaOH}$-treated barley to cattle as opposed to the same barley without $\mathrm{NaOH}$ treatment, produced a twofold increase in the $\mathrm{C}_{18: 2, n-6}$ concentration of muscle. In addition, if the $\mathrm{NaOH}$-treated barley was fed as a vitamin $\mathrm{E}$ and Se-deficient diet, there was an increased concentration of $C_{20: 4}, n-6$ in heart and muscle. These observations confirm that the PUFA profile of tissues varies as a result of dietary factors even when the PUFA input per se does not change. When $C_{18: 3}, n-3$ was added to the ration as protected fat, there was an increase in the $C_{18: 3}, n-3$ concentration of phospholipids of skeletal and cardiac muscle within 4-6 d of feeding. We concluded that $C_{18: 3}, n-3$ was responsible for the initiation of the nutritional degenerative myopathy. Subsequently, experiments have shown this $C_{18: 3}, n-3$ fatty acid-induced myopathy is completely preventable by pretreatment with either vitamin $\mathrm{E}$ or Se (Rice, 1984). 
These experiments confirm that increasing the dietary input of PUFA will modulate the PUFA concentration of subcellular membranes. Whilst such manipulations of $n-3$ fatty acid input may have beneficial effects on certain target tissues, particularly macrophages, leucocytes and platelets, where they act as preferential substrates for cyclo-oxygenase and produce metabolites with a lowered physiological response compared with those of the arachidonic acid cascade, these fatty acids may have detrimental effects on other cells such as cardiocytes, purkinje fibres and myocytes as shown in our studies. Our studies have not determined the exact mechanism whereby

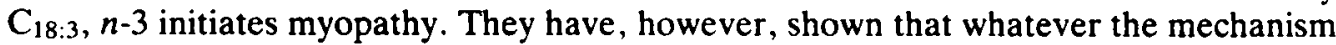
of initiation, the detrimental effect can be overcome by maintaining high levels of vitamin $\mathrm{E}$ or glutathione peroxidase, or both, in the target tissues.

\section{Vitamin E}

Vitamin $\mathrm{E}$ is the generic name for a group of lipid-soluble compounds known as tocopherols and tocotrienols. The chemical structures of the various vitamin $\mathrm{E}$ derivatives are shown in Fig. 1. The degree of methylation of the chromanol ring results in the four different members of each family, i.e. $\alpha, \beta, \gamma$ and $\delta$. All these members are found in varying concentrations in plants.

Most recent developments in our understanding of the vitamin $\mathrm{E}$ status and requirements of domestic livestock and the relation of this vitamin to the diseases listed in Table 1 , stem from improvements in analytical techniques. Current assay systems are based on high-performance liquid chromatographic (HPLC) separation and fluorometric detection of vitamin $E$ isomers. These techniques have demonstrated that previous colorimetric and direct fluorometric assays have overestimated the vitamin $E$ content of feeds (McMurray et al. 1980) and blood plasma (McMurray \& Blanchflower, 1979). In addition HPLC methods can separate, detect and quantify the various vitamin $E$ isomers found in feedstuffs, i.e. $\alpha-, \beta-, \gamma$-and $\delta$-derivatives of both the tocopherols and the tocotrienols. This has helped partially to resolve the question of availability or effectiveness of these various derivatives in the animal.

Leth \& Sondergaard (1977) ascribed biopotencies of $100,56,16$ and $0.5 \%$ to the $\alpha$-, $\beta-, \gamma$ - and $\delta$-tocopherols using a rate of fetal resorption assay. Similar derivatives of the

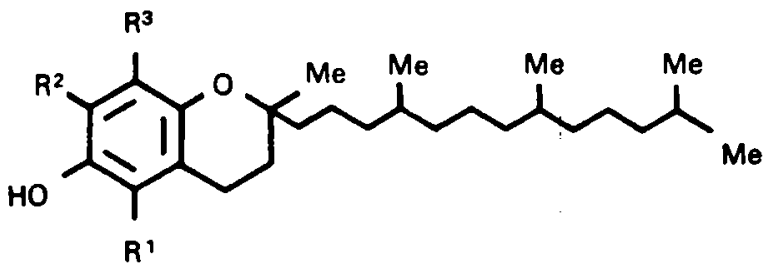

\begin{tabular}{|c|c|c|c|}
\hline Compound & $\mathbf{R}^{1}$ & $\mathbf{R}^{2}$ & $\mathbf{R}^{3}$ \\
\hline$\alpha$-Tocopherol & Me & Me & Me \\
\hline B-Tocopherol & $\mathrm{Me}$ & H & Me \\
\hline$\gamma$-Tocopherol & $H$ & Me & $\mathrm{Me}$ \\
\hline 8-Tocopherol & H & $H$ & $\mathrm{Me}$ \\
\hline
\end{tabular}

Fig. 1. Chemical formula for vitamin $E$ showing the differences in the structure of the various derivatives. The tocotrienols differ only in that the phytol chain contains three double bonds. Me, methyl group. 
Table 2. Levels of $\alpha$-tocopherol in plasma of three groups of calves $(A, B$ and $C)$ which were turned out to spring grass at 2-weekly intervals (from Rice \& Kennedy, 1988a)

(The Table shows the $\alpha$-tocopherol levels in plasma before turnout when the animals were eating a barley diet and $12 \mathrm{~d}$ after turnout to grass. Values are means and standard deviations for six calves)

\begin{tabular}{|c|c|c|c|c|}
\hline \multirow[b]{3}{*}{ Group } & \multicolumn{4}{|c|}{ Plasma $\alpha$-tocopherol $(\mu \mathrm{g} / \mathrm{l})$} \\
\hline & \multicolumn{2}{|c|}{ Before turnout } & \multicolumn{2}{|c|}{$12 \mathrm{~d}$ after turnout } \\
\hline & Mean & SD & Mean & SD \\
\hline A & 0.70 & 0.23 & 1.99 & 0.57 \\
\hline B & 0.67 & $0 \cdot 13$ & 3.09 & 1.07 \\
\hline $\mathrm{C}$ & 0.88 & 0.26 . & 4.90 & 0.5 \\
\hline
\end{tabular}

tocotrienol family had only $16 \%$ of the activity of the corresponding tocopherol. Leth \& Sondergaard (1977) suggested, therefore, that the amount of each of these derivatives in a feedstuff should be measured and multiplied by a factor relative to its biological activity. The summed 'total vitamin E' of the feed could therefore be calculated. More recent work has called this approach into question. Using HPLC techniques, it has been shown that the only vitamin $E$ derivative present in high concentrations in the tissues of pigs and cattle is $\alpha$-tocopherol. This is so even when the diet contains proportionately higher concentrations of other tocopherols or tocotrienols (McMurray \& Rice, 1982; Rice \& McMurray, 1982). Our studies have not defined the mechanism for the selective incorporation of $\alpha$-tocopherol into tissues, i.e. whether it relates to absorption, transport mechanisms, or excretion processes. However, we feel that there is sufficient evidence to support our contention that the only relative vitamin $E$ derivative in the feed of cattle and sheep, and possibly other livestock, that should be measured is $\alpha$-tocopherol.

Our work has demonstrated a wide variation in the $\alpha$-tocopherol content of feeds eaten by livestock. The concentration present in feed is normally proportional to the sum of the PUFA in the plant or seed (Booth, 1964). In animal tissues, however, the $\alpha$-tocopherol concentration is normally proportional to the amount consumed in the feed. For example, steers eating grass $(60-80 \mathrm{mg} \alpha$-tocopherol $/ \mathrm{kg}$ dry weight) have plasma $\alpha$-tocopherol concentrations of $4.3(\mathrm{SD} 1.7) \mathrm{mg} / \mathrm{l}$ whereas the same calves had a concentration of $0.5(\mathrm{sD} \mathrm{0.2)} \mathrm{mg/l} \mathrm{within} 3$ weeks of eating a barley-based diet $(1 \mathrm{mg}$ $\alpha$-tocopherol/kg dry weight) (Rice \& McMurray, 1986).

The concentration of $\alpha$-tocopherol in the feed which an animal is consuming is not always, however, a good indicator of the vitamin $E$ status of the animal. In three groups of calves eating spring grass with a very similar vitamin $\mathrm{E}$ content the mean plasma $\alpha$-tocopherol content varied from 2 to $4 \mathrm{mg} / \mathrm{l}$ between groups (Table 2). The reason for these differences was related to unidentified constituents in the young spring grass which caused diarrhoea in some of these calves and apparently decreased vitamin $E$ absorption.

For this reason, therefore, it would seem logical that the vitamin E status of livestock should be defined in terms of $\alpha$-tocopherol alone and, in addition, that studies on availability and effectiveness should relate to tissue and not to feed concentrations of the vitamin.

The importance of measuring tissue concentrations is further borne out by some recent research into the relation between $\alpha$-tocopherol intake and the occurrence of (1) dietetic microangiopathy (mulberry heart disease) in pigs in field outbreaks of disease and (2) the occurrence of skeletal and cardiac myopathy in Atlantic salmon with pancreatic disease. 
Table 3. $\alpha$-Tocopherol $(\mathrm{mg} / \mathrm{kg})$ status of feed and tissues of diseased and control salmon and pigs

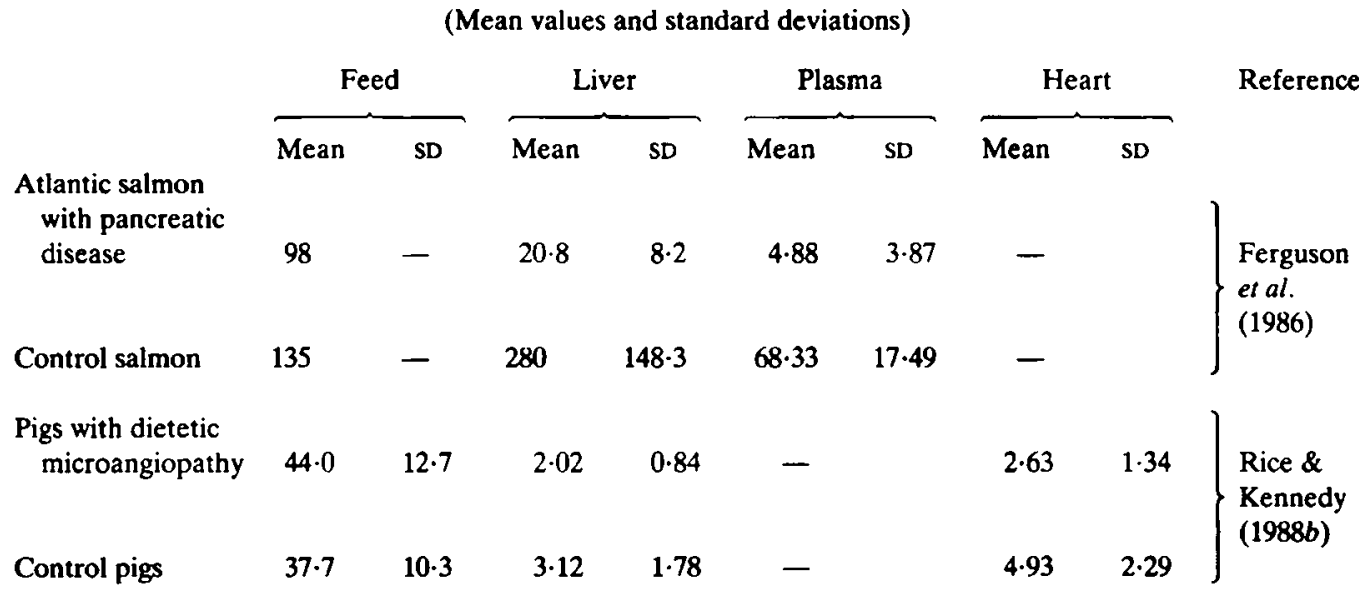

In the pig study the feed concentrations of $\alpha$-tocopherol were not very different between control and affected groups (Table 3). However, the tissue concentrations were substantially different, particularly in heart tissue, i.e. in the target tissue diseased by vitamin E deficiency. Again, the minor differences in feed $\alpha$-tocopherol between diseased and normal salmon are insufficient to account for the massive differences in plasma and liver $\alpha$-tocopherol found in Atlantic salmon with pancreatic disease (Table $3)$. In both instances vitamin $E$ availability must have been effected by other factors. Both these examples again highlight the importance of measuring availability of the nutrient in terms of its availability for incorporation into the target tissue.

\section{Se}

The main function of Se in mammalian tissues is as an integral component of the enzyme GSH-Px (Rotruck et al. 1973). In spite of recent work which has pointed towards other additional roles for $\mathrm{Se}$ in biological systems, isolation and identification of other functional forms are still awaited. It is convenient that GSH-Px concentration and activity in tissues is positively related to Se intake in most livestock species. As a consequence, the activity of this enzyme in conveniently collected samples (e.g. erythrocytes, platelets and plasma) is often measured to assess the Se status of animals. The principle of this approach is good and for this reason it has been used to evaluate the availability of Se from various food sources. Gabrielsen \& Opstvedt (1980) expressed the availability of Se from various feedstuffs as the ability of the Se from a particular source to increase plasma GSH-Px concentrations in chicks. Currently this appears to be the best method for assessing availability. The method is not, however, without its limitations in that plasma is not a target organ of Se-deficiency disease and it may well be more appropriate to measure GSH-Px response to dietary Se in the target cell where an optimum concentration of the enzyme is essential. It is also known that the kinetic response of GSH-Px synthesis to different inputs of dietary Se varies substantially between tissues, being, for example, more rapid in plasma than in erythrocytes (McMurray et al. 1986). Therefore information obtained from studies relating to plasma or erythrocyte GSH-Px may not bear a direct relation to the availability of Se for GSH-Px synthesis in the target cell. 
Table 4. Effect of diluting human and sheep whole blood with Drabkins reagent on the activity of glutathione peroxidase (EC 1.11.1.9; GSH-Px) 10 min after dilution (from Blanchflower et al. 1986)

\begin{tabular}{rcc} 
Diluent & \multicolumn{2}{c}{ GSH-Px (i.u./g haemoglobin) } \\
\cline { 2 - 3 } Glutathione & Human & Sheep \\
Drabkins $0.5 \mathrm{M}$ & 33 & 718 \\
$1.0 \mathrm{M}$ & 33 & 300 \\
$2.0 \mathrm{M}$ & 31 & 205 \\
$5.0 \mathrm{M}$ & 25 & 156 \\
& 21 & 123
\end{tabular}

There would be an additional benefit to measuring GSH-Px concentration in the target cell in that most dietary factors which interfere with Se metabolism and increase the risk of disease, also depress GSH-Px concentrations. Consequently it is possible that specific toxins or 'interfering factors' may modulate GSH-Px synthesis or turnover in a specific target tissue but not necessarily in plasma or erythrocytes.

There is consequently a lot of research required on the response of 'target tissue' GSH-Px to varying Se inputs and to other modulating factors. If it can be shown that changes in GSH-Px concentration in plasma, erythrocytes or platelets are very strongly positively correlated to changes in its concentration in target organs, it will be more justifiable to continue the practice of assessing Se status by measuring the GSH-Px concentration in 'remote' tissues, for reasons other than ease of sampling.

This aside, those carrying out research on Se are fortunate to have a trace-elementdependent enzyme which responds to nutritional input. Those working on zinc and other trace nutrients would be overjoyed to have such a convenient 'handle' for their experiments. However, recent work has demonstrated that not all of what we know about this enzyme is being applied in the clinical situation. It has been known for many years that GSH-Px is irreversibly inactivated by cyanide in the oxidized form (Prohaska et al. 1977), yet cyanide is added to the assay system in many diagnostic laboratories simply because this was first recommended by Paglia \& Valentine (1967). The degree of inactivation of GSH-Px by Drabkins reagent has recently been quantified by Blanchflower et al. 1986 (Table 4). These authors also demonstrated a similar decline as a result of storage, although the enzyme can be reactivated by pre-incubation of the sample with reduced glutathione. These factors have caused problems in clinical laboratories for years. Recently, the analytical method for measurement of the enzyme in erythrocytes has been optimized to eliminate some of these problems (Blanchflower et al. 1986). Indeed, a diagnostic kit based on this method together with a GSH-Px standard has recently been developed and is now commercially available (Rice \& Blanchflower, 1986). This should help to standardize the assay and allow inter-laboratory comparison of results.

It is now apparent that there is probably more than one form of GSH-Px in tissues. Takahashi et al. (1987) have demonstrated immunological differences between plasma and tissue GSH-Px and Sunde et al. (1988) have demonstrated differences in the amino acid composition and configuration of different forms of the enzyme. Hawkes et al. (1985) and McMurray et al. (1986) have demonstrated that some of the different forms of the enzyme may be strongly bound to the tissue stroma. Forward \& Almog (1985) have 
separated two types of GSH-Px from tissue. The resulting hypothesis from all of this work may be that there are various forms of GSH-Px and that only those which are lypophilic and can maintain close apposition to phospholipids will be biologically effective in removing free-radical-induced lipid hydroperoxides from the PUFA environment of the membrane. If this is the case then specific antisera to this lypophilic form could be produced which would then be used to localize and quantify the activity of this form in target cells. This would then provide an ideal method for assessing the availability of different forms of Se in that one could measure their ability to maintain optimum levels of this specific GSH-Px form in the target tissue.

\section{Interactions}

Our work on bovine myopathy has demonstrated that, in spite of the ability of the rumen to hydrogenate a lot of dietary PUFA, all the pathological and clinical manifestations of the disease can be explained on the basis of vitamin $E$ ( $\alpha$-tocopherol) and Se (GSH-Px) deficiency in tissue, or PUFA excess, or both. It has also shown that even minor modifications in dietary input can have profound influences on the proportions and concentrations of lipid-peroxidation antagonists and protagonists in the subcellular environment. The pathology resulting from these imbalances will be affected by a number of variables in the subcellular membrane where peroxidation is ongoing. These will include the genetically predetermined degree of unsaturation of PUFA in the membrane; the degree of unsaturation resulting from both dietary input and from factors which modulate desaturase and chain elongase activity; the intensity and duration of peroxidation initiation, whether cyclo-oxygenase-lipoxygenase or chemically driven; the genetically determined ability of the membrane at risk to assimilate and store peroxidation antagonists such as vitamin $\mathrm{E}, \mathrm{GSH}-\mathrm{Px}$, catalase $(E C$ 1.11.1.6) and superoxide dismutase (EC 1.15.1.1); levels of these antagonists in the membranes as a result of dietary input or other factors which modulate their availability, or both; and, most importantly, by the function of the organelle in which the membrane has been damaged.

Although our work has not examined all these variables it has demonstrated that a minimum tripartite interaction of vitamin E, Se and PUFA will explain all the clinical and pathological manifestations of myopathy observed in young ruminants under field conditions. The findings of this research suggest that a continued haphazard use of PUFA in vitamin E- and Se-deficient diets is scientifically questionable. It is no longer acceptable to use high levels of stripped maize oil, lard, soya-bean oil, etc. to strip the animals' vitamin $E$ reserves, as did researchers 40 years ago. The incorporated fatty acids will have many specific biological functions, some of which will be vitamin-E-dependent whereas others will not. Because of the close interdependence of vitamin E, GSH-Px and PUFA, each must be considered as a variable in future experimental protocols, or at least the specific rates of their incorporation into the experimental diets must be well defined. By this I mean that a statement that a diet contains ' $200 \mathrm{~g}$ stripped $\mathrm{lard} / \mathrm{kg}$ ' is a meaningless term. This tells us nothing of the fatty acid profile of the fat. The specific inclusion levels of the constituent $n-6$ and $n-3$ and other fatty acids should be given. There should also be a vitamin $E$ analysis to determine that all the vitamin $E$ isomers have in fact been stripped.

Current analytical techniques have allowed us to begin to understand the mechanisms by which lipid-free-radical-mediated diseases are produced. The variation in concentrations of substrates in the subcellular environment which either promote or prevent lipid peroxidation usually helps us to explain the diversity of tissues affected by peroxidative attack both between and within species of animals (Table 1). However, as we continue to develop techniques which will permit us to measure the active concentrations of these 
pro- and antioxidants in the subcellular membrane where free radicals are formed, e.g. by immunohistochemical techniques, then we will be able to more fully understand the unquestioned importance of vitamin $\mathrm{E}$ and $\mathrm{Se}$ in preventing free-radical-mediated disease. Moreover, we will be able to move away from the classical definitions of assessment of nutritional adequacy of these micro-nutrients to an era when where we can define availability in terms of the ability of the nutrient from a certain source to produce and maintain optimum concentrations of vitamin $\mathrm{E}$ and GSH-Px at the subcellular level where it is required. No doubt as we progress along this route more information will become available on the effect of additional dietary and physiological factors which will both detrimentally and beneficially modify the availability and activity of these peroxidation antagonists in tissues. These should not serve to distract us from the goal of redefining dietary adequacy, not in terms of dietary inclusion levels nor the concentration in remote 'tissues' which are easily sampled, but in the subcellular site of action where they are required.

\section{REFERENCES}

Blanchflower, W. J., Rice, D. A. \& Davidson, W. B. (1986). Biological Trace Element Research 11, 89-100.

Booth, V. H. (1964). Pytochemistry 3, 273-276.

Ferguson, H. W., Rice, D. A. \& Lynas, J. K. (1986). Veterinary Record 119, 297-299.

Forward, R. \& Almog, R. (1985). Journal of Chromatography 330, 383-387.

Gabrielson, B. O. \& Opstvedt, J. (1980). Journal of Nutrition 110, 1096-1100.

Gurr, M. I. (1983). Progress in Lipid Research 22, 257-287.

Hawkes, W. C., Wilhelmsen, E. C. \& Tappel, A. L. (1985). Journal of Inorganic Biochemistry 25, 77-93.

Johnston, P. V. (1985). Advances in Lipid Research 21, 103-141.

Leth, T. \& Sondergaard, H. (1977). Journal of Nutrition 107, 2236-2243.

McMurray, C. H. \& Blanchflower, W. J. (1979). Journal of Chromatography 178, 525-531.

McMurray, C. H., Blanchflower, W. J. \& Rice, D. A. (1980). Journal of the Association of Official Analytical Chemists 63, 1258-1261.

McMurray, C. H., Davidson, W. B., Blanchflower, W. J. \& Rice, D. A. (1986). In Selenium in Biology and Medicine, pp. 354-359 [G. F. Combs and J. E. Spallholz, editors]. Westport, CT: Avi Publishing Co.

McMurray, C. H. \& Rice, D. A. (1982). Irish Veterinary Journal 36, $57-67$.

McMurray, C. H., Rice, D. A. \& Kennedy, S. (1983). Biology of Vitamin E, CIBA Symposium no. 101, pp. 201-233. London: Pitman Books.

Paglia, D. E. \& Valentine, W. N. (1967). Journal of Laboratory Clinical Medicine 70, 158-169.

Prohaska, J. R., OI, S.H., Hoekstra, W. G. \& Ganther, H. E. (1977). Biochemical and Biophysical Research Communications 74, 64-71.

Rice, D. A. (1984). Induction of nutritional degenerative myopathy in the bovine. PhD Thesis, Queen's University, Belfast.

Rice, D. A. \& Blanchflower, W. J. (1986). Veterinary Record 118, 479-480.

Rice, D. A., Blanchflower, W. J., \& McMurray, C. H. (1981). Veterinary Record 109, 161-162.

Rice, D. A. \& Kennedy, S. (1988a). British Veterinary Journal 143 (In the Press).

Rice, D. A. \& Kennedy, S. (1988b). In Trace Elements Metabolism in Man and Animals, vol. 6. New York: Plenum Publishing Co. (In the Press).

Rice, D. A., Kennedy, S., McMurray, C. H. \& Blanchflower, W. J. (1986). Proceedings 6th International Conference on Production Disease in Farm Animals, Belfast, pp. 229-233.

Rice, D. A. \& McMurray, C. H. (1982). Recent Information on Vitamin E and Selenium in Ruminants, Roche Vitamin Symposium, London.

Rice, D. A. \& McMurray, C. H. (1986). Veterinary Record 118, 173-176.

Rotruck, J., Pope, A., Ganther, H., Swanson, A., Hafeman, D. \& Hoekstra, W. (1973). Science 179, 588-590.

Stubbs, C. D. \& Smith, A. D. (1984). Biochimica et Biophysica Acta 779, 89-137.

Sunde, R. A., Knight, S. \& Evenson, J. K. (1988). In Trace Element Metabolism in Man and Animals, vol. 6. New York: Plenum Publishing Co. (In the Press).

Takahashi, K., Avissar, N., Whitin, J. \& Cohen, H. (1987). Archives of Biochemistry and Biophysics 256, $677-686$. 